\title{
(2) OPEN ACCESS \\ COVID-19 in children: analysis of the first pandemic peak in England
}

\author{
Shamez N Ladhani 지 ${ }^{1,2}$ Zahin Amin-Chowdhury, ${ }^{1}$ Hannah G Davies, ${ }^{1,2}$ \\ Felicity Aiano, ${ }^{1}$ Iain Hayden, ${ }^{1}$ Joanne Lacy, ${ }^{1}$ Mary Sinnathamby, ${ }^{1}$ Simon de Lusignan, ${ }^{3,4}$ \\ Alicia Demirjian, ${ }^{4,5,6}$ Heather Whittaker, ${ }^{7}$ Nick Andrews, ${ }^{7}$ Maria Zambon, ${ }^{8}$ \\ Susan Hopkins, ${ }^{4}$ Mary Elizabeth Ramsay ${ }^{1,9}$
}

\section{${ }^{1}$ Immunisation and}

Countermeasures Division, Public Health England, London, UK

${ }^{2}$ Paediatric Infectious Diseases Research Group, St. George's University of London, London, UK

${ }^{3}$ Nuffield Department of Primary Care Health Sciences, University of Oxford, Oxford, UK

${ }^{4}$ Antimicrobial Resistance and Hospital-acquired Infections Department, Public Health England, London, UK

${ }^{5}$ Paediatric Infectious Diseases and Immunology, Evelina

London Children's Hospital, London, UK

${ }^{6}$ Faculty of Life Sciences and Medicine, King's College

London, London, UK

${ }^{7}$ Statistics, Modelling and Economics Department, Public Health England, London, UK

${ }^{8}$ Microbiological Services

Colindale, Public Health

England, London, UK

${ }^{9}$ London School of Hygiene and

Tropical Medicine, London, UK

\section{Correspondence to} Dr Shamez N Ladhani, Immunisation and

Countermeasures Division,

Public Health England Colindale, London NW9 5EQ, UK;

DrShamez@aol.com

Received 24 June 2020

Revised 20 July 2020

Accepted 23 July 2020

\section{Check for updates}

(C) Author(s) (or their employer(s)) 2020. Re-use permitted under CC BY-NC. No commercial re-use. See rights and permissions. Published by BMJ.

To cite: Ladhani SN, AminChowdhury Z, Davies HG, et al. Arch Dis Child Epub ahead of print: [please

include Day Month Year]. doi:10.1136/

archdischild-2020-320042

\section{ABSTRACT}

Objectives To assess disease trends, testing practices, community surveillance, case-fatality and excess deaths in children as compared with adults during the first pandemic peak in England.

Setting England.

Participants Children with COVID-19 between January and May 2020.

Main outcome measures Trends in confirmed COVID-19 cases, severe acute respiratory syndrome coronavirus 2 (SARS-CoV-2) positivity rates in children compared with adults; community prevalence of SARSCoV-2 in children with acute respiratory infection (ARI) compared with adults, case-fatality rate in children with confirmed COVID-19 and excess childhood deaths compared with the previous 5 years.

Results Children represented 1.1\% $(1,408 / 129,704)$ of SARS-CoV-2 positive cases between 16 January 2020 and 3 May 2020. In total, 540305 people were tested for SARS-COV-2 and 129,704 (24.0\%) were positive. In children aged $<16$ years, 35,200 tests were performed and 1408 (4.0\%) were positive for SARS-CoV-2, compared to $19.1 \%-34.9 \%$ adults. Childhood cases increased from mid-March and peaked on 11 April before declining. Among 2,961 individuals presenting with ARI in primary care, 351 were children and 10 (2.8\%) were positive compared with $9.3 \%-45.5 \%$ in adults. Eight children died and four (case-fatality rate, $0.3 \% ; 95 \% \mathrm{Cl}$ $0.07 \%$ to $0.7 \%$ ) were due to COVID-19. We found no evidence of excess mortality in children.

Conclusions Children accounted for a very small proportion of confirmed cases despite the large numbers of children tested. SARS-CoV-2 positivity was low even in children with ARI. Our findings provide further evidence against the role of children in infection and transmission of SARS-COV-2.

\section{INTRODUCTION}

Experience from countries recovering from large outbreaks of COVID-19 shows that children rarely develop severe or critical illness, ${ }^{1}$ or die from the infection as compared with adults. ${ }^{2}{ }^{3}$ It is still unclear why the epidemiology, clinical features and outcomes of COVID-19 are so different in children compared with adults. COVID-19, caused by the severe acute respiratory syndrome coronavirus 2 (SARS-CoV-2), typically presents as an acute respiratory illness. Common symptoms include fever and cough, as well as fatigue, chest tightness and
What is already known on this topic?

Children account for only a small proportion of confirmed cases of COVID-19.

- Most childhood cases of COVID-19 are mild and self-limiting.

- Whether this is due to limited testing for severe acute respiratory syndrome coronavirus 2 (SARS-CoV-2) in children is not known.

\section{What this study adds?}

- Despite widespread testing, SARS-CoV-2 positivity rates throughout the pandemic peak were low in children compared with adults, including those presenting with acute respiratory infection in the community.

- Case-fatality rate in children with COVID-19 was $<0.5 \%$ and there was no evidence of excess childhood mortality in children during the first wave of the COVID-19 pandemic in England.

dyspnoea, although individual symptoms or clusters of symptoms have moderate to low sensitivity and specificity for the infection. ${ }^{4}$ While most individuals recover without specific treatment or hospitalisation, some, especially older adults, may progress to acute respiratory distress syndrome and multiorgan failure, which is associated with high case-fatality rates despite early and aggressive management in intensive care settings. ${ }^{56}$

In England, with a population of 55 million individuals, the first imported cases of COVID-19 were identified at the end of January 2020. Initially, case numbers increased slowly and were related to imported cases. However, despite contact tracing and testing individuals who met a geographic and symptom-based case definition, cases with no clear transmission chains or overseas travel started to emerge at the end of February. These cases were detected through community sentinel surveillance schemes, and cases without overseas travel were diagnosed in intensive care units (ICUs), through ICU sentinel surveillance, on the first week of March. Cases increased rapidly during the subsequent 2 weeks with evidence of community transmission across the country. 
On 12 March, the UK moved from a containment to a delay phase of the government response to the pandemic, with emphasis placed on slowing the spread of the virus, lowering the peak impact on hospital and ICU services and pushing it away from the winter season; this included the recommendation for anyone with fever or cough to stay at home. Available testing capacity from individuals with mild symptoms in the community was also shifted to those who required hospitalisation and for outbreak investigations in closed institutional settings (such as care homes and prisons). On 23 March, the UK government closed all but essential shops and services and recommended that the entire population stayed at home unless they provided an essential service or were a key worker.

In England, Public Health England (PHE) has been conducting enhanced national surveillance of COVID-19 since the first cases were reported in Wuhan, China, in December 2019. ${ }^{7}$ While adults rightly remained the primary focus of national surveillance, an extensive surveillance strategy was also established to contemporaneously monitor childhood COVID-19 in England. ${ }^{7}$

Currently, COVID-19 cases have peaked and hospital admissions are the lowest since 23 March in England. ${ }^{8}$ Here, we describe the surveillance, epidemiology and outcomes of childhood COVID-19 during the first peak. In addition to disease trends, we assessed SARS-CoV-2 positivity rates in different childhood age groups compared with adults, community surveillance of SARS-CoV-2 in children and adults presenting with acute respiratory infection in primary care, cause of death in SARS-CoV-2-positive children and monitoring excess deaths in children compared with the previous 5 years.

\section{METHODS}

PHE initiated COVID-19 surveillance in England after the first cluster of cases was reported in Wuhan, Hubei Province, China in December 2019. In early January, an RT-PCR diagnostic test for SARS-CoV-2 was developed and validated by PHE. By early March 2020, the tests were also delivered by PHE regional laboratories and National Health Service (NHS) laboratories across England. Case definitions for SARS-CoV-2 testing varied over the course of the first peak of the pandemic (table 1). ${ }^{9}$ Throughout this period, confirmed cases and their close contacts were isolated to prevent transmission into the community. During the delayed phase of outbreak control, emphasis was shifted to testing those presenting to hospital with suspected COVID-19 with the aim of rapidly diagnosing cases and protecting those who were SARS-CoV-2 negative. Clinical follow-up of confirmed cases in children aged $<16$ years began at the start of the pandemic and is ongoing. ${ }^{7}$ Fatal cases were identified through regular linkage with the Patient Demographic Service, an electronic database of all NHS patients, as well as direct reporting of deaths by paediatricians and local Health Protection Teams.

\section{SARS-COV-2 POSITIVITY}

The respiratory DataMart system and Second Generation Surveillance System (SGSS) were used to assess SARS-CoV-2 testing in different age groups. ${ }^{10}$ SGSS receives reports of all positive SARS-CoV-2 tests, as part of its laboratory data capture. In addition, the previous DataMart system and SGSS were modified to include negative results from NHS and Public Health laboratories, which were then consolidated in a unified database which used a probabilistic algorithm to remove duplicates and results from patients that had tested positive. Positive results from one laboratory that only reported positives and results from patients outside England were excluded.
Table 1 Summary of case definitions for population testing for SARS-CoV-2 in England

\begin{tabular}{|c|c|}
\hline Time period & Case definition \\
\hline Before 7 February 2020 & $\begin{array}{l}\text { Epidemiological criteria } \\
\text { In the } 14 \text { days before the onset of illness: } \\
\text { travel to China OR contact with a confirmed case of } \\
\text { COVID-19; } \\
\text { and Clinical criteria } \\
\text { severe acute respiratory infection requiring admission } \\
\text { to hospital with clinical or radiological evidence of } \\
\text { pneumonia or acute respiratory distress syndrome; } \\
\text { OR acute respiratory infection of any degree of severity, } \\
\text { including at least one of shortness of breath (difficult } \\
\text { breathing in children) or cough (with or without fever); } \\
\text { OR fever with no other symptoms. }\end{array}$ \\
\hline From 7 February 2020 & $\begin{array}{l}\text { Epidemiological criteria } \\
\text { In the } 14 \text { days before the onset of illness: } \\
\text { travel to affected countries, including transit, for any } \\
\text { length of time, in these countries OR contact with a } \\
\text { confirmed case of COVID-19; } \\
\text { and Clinical criteria } \\
\text { severe acute respiratory infection requiring admission } \\
\text { to hospital with clinical or radiological evidence of } \\
\text { pneumonia or acute respiratory distress syndrome; } \\
\text { OR } \\
\text { incute respiratory infection of any degree of severity, } \\
\text { including at least one of shortness of breath (difficult } \\
\text { breathing in children) or cough (with or without fever); } \\
\end{array}$ \\
\hline From 13 March 2020 & $\begin{array}{l}\text { Inpatient definition } \\
\text { and } \\
\text { OR } \\
\text { pneumouiring admission to hospital; } \\
\text { OR } \\
\text { acute respiratory distress syndrome; } \\
\text { of the following respiratory symptoms, which must } \\
\text { be of acute onset: persistent cough (with or without } \\
\text { sputum), hoarseness, nasal discharge or congestion, } \\
\text { shortness of breath, sore throat, wheezing or sneezing. }\end{array}$ \\
\hline
\end{tabular}

*/mported cases were defined as cases with travel to countries with known COVID-19 circulation at the time or with contact with a confirmed case while abroad within a maximum incubation period of their onset of symptoms. tSecondary cases were defined as cases that had contact with a confirmed or probable/suspected case in the UK and did not fit the definition of an imported case.

¥Sporadic cases were defined as cases with no travel history to countries with known COVID-19 circulation, and no known contact with a confirmed case. SARS-CoV-2, severe acute respiratory syndrome coronavirus 2 .

\section{COMMUNITY SWABBING}

Community-based surveillance for influenza-like illness was established by the Royal College of General Practitioners Research and Surveillance Centre creating a network of general practices across England and Wales $>50$ years ago. ${ }^{11} 12$ Adults and children presenting to around 100 participating general practices with an influenza-like illness (defined as fever with one systemic and one respiratory symptom) had a nasopharyngeal swab taken for testing. Clinicians were instructed to sample one or two patients a week. Details of the swabbing scheme are detailed elsewhere. ${ }^{11}$ In March 2020, this surveillance was extended for SARS-CoV-2 testing in the community, including expanding the number of virology sampling practices to $300 .{ }^{11}$ 

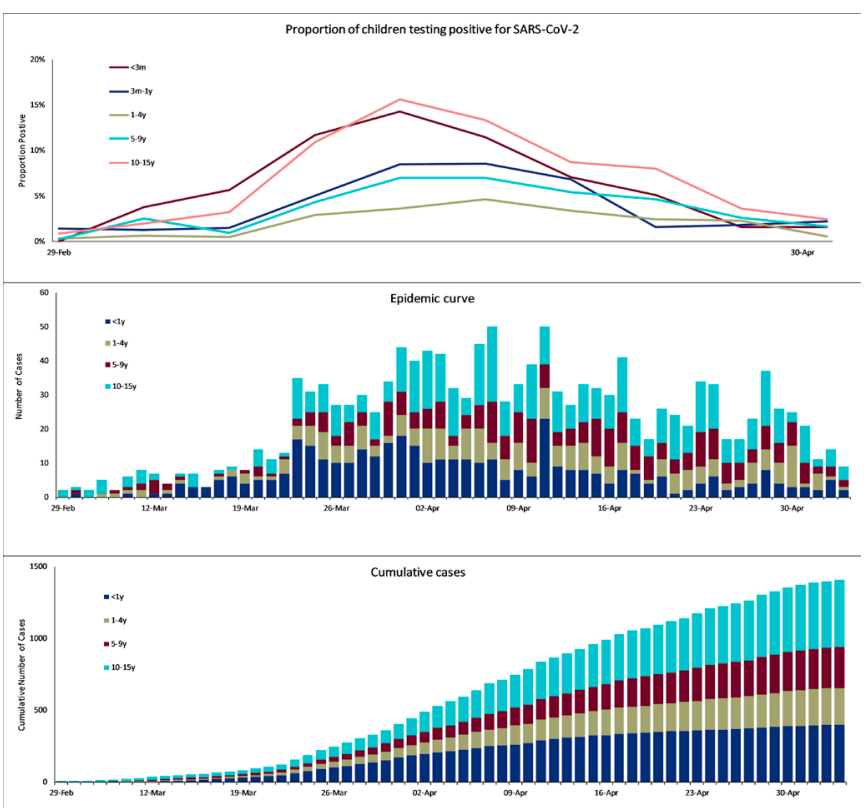

Figure 1 Epidemic curve (A), cumulative number of confirmed cases (B) and proportion of test positives (C) by age group for COVID-19 in children during the first pandemic peak (February to May 2020) in England.

\section{MORTALITY TRENDS}

Data on death registrations until midnight on each day are sent the next day to PHE by the General Registry Office. Death registrations since 1 January 2015 were aggregated by age in years, date of death, date of registration, gender and region. To model weekly all-cause deaths by week of death in children, the Euromomo algorithm was used to fit a trend to deaths in the past 5 years using only spring and autumn data (to avoid potential spikes from influenza and cold weather). The data were modelled using a Poisson distribution with rescaling based on overdispersion and an expected number calculated along with predictions limits (+2 Z-scores). To account for delays from death to registration, which could be long if reported to a coroner, an adjustment to data from the previous 50 weeks was applied using a model of the proportion of deaths registered with each time lag from 0 to 50 weeks. The same model is used to estimate excess mortality in older age groups with the exception that a cosine wave is used to capture the usual pattern of higher deaths in the winter compared with summer. Results of excess mortality trends are reported to Euromomo each week and presented as a Z-score analysis (https://www.euromomo.eu/). ${ }^{13}$

\section{RESULTS}

\section{EPIDEMIOLOGY}

Between 1 January and 3 May 2020, 129704 (24.0\%) out of 540305 people tested positive for SARS-CoV-2 in England. In children, the first confirmed cases were reported on 29 February 2020. Cases started to increase during the second week of March and peaked on 11 April 2020 before declining gradually, corresponding to the trends observed in adults (figure 1). COVID-19 cases were confirmed across the country, with greater numbers diagnosed in large cities (figure 2). Children accounted for 1408 (1.1\%) confirmed cases across all age groups and $742(52.7 \%)$ were male. The median age of childhood cases was 5.9 years, with higher number of cases in infants and older adults (figure 3).

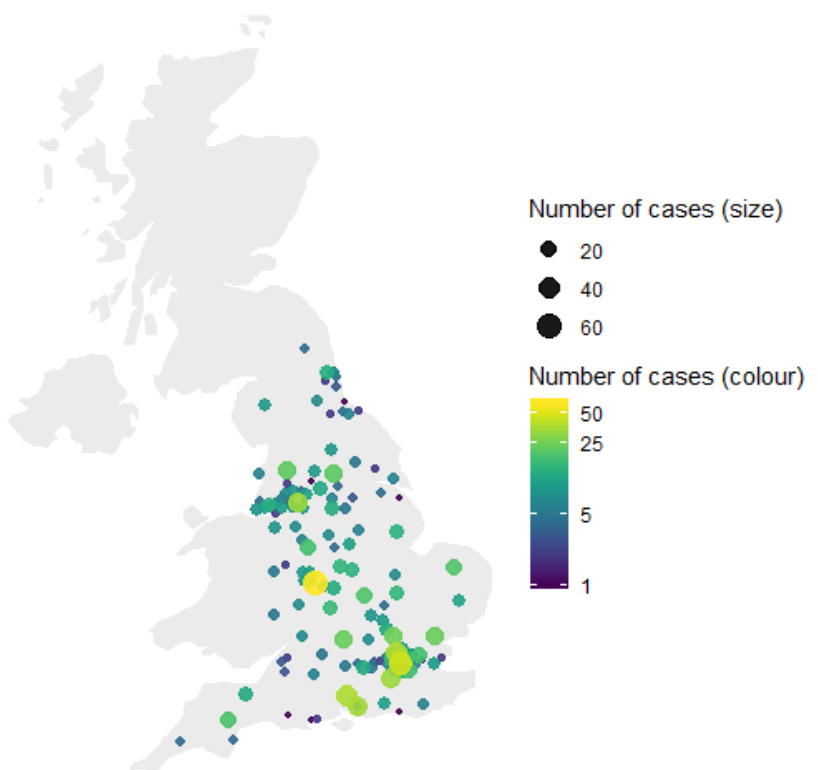

Figure 2 Distribution of confirmed COVID-19 cases in children during the first pandemic peak (February to May 2020) in England.

Test positivity rates by age

Children represented $6.6 \%(n=35200)$ of 536278 people with reported age who were tested for SARS-CoV2 and 1408/35 200 (4.0\%) children tested were positive, compared with $19.1 \%$ $34.9 \%$ of adults (figure 4). Infants aged $<3$ months (272/4072), followed by older infants (128/3358) and children aged 1 year $(107 / 4280)$ had the most tests performed and the highest number of positive tests among children aged $<16$ years (figure 1 ). Testpositivity rates varied over the course of the pandemic, peaking around the same time as the peak in COVID-19 cases (figure 1).

\section{Community surveillance of acute respiratory infection}

Overall, 2968 individuals with influenza-like illness presenting to any of the participating general practices had nasopharyngeal swabs taken and $10(2.8 \%)$ of 351 children were positive compared with $9.3 \%(88 / 946)$ in those aged $15-44$ years, $18.6 \%$

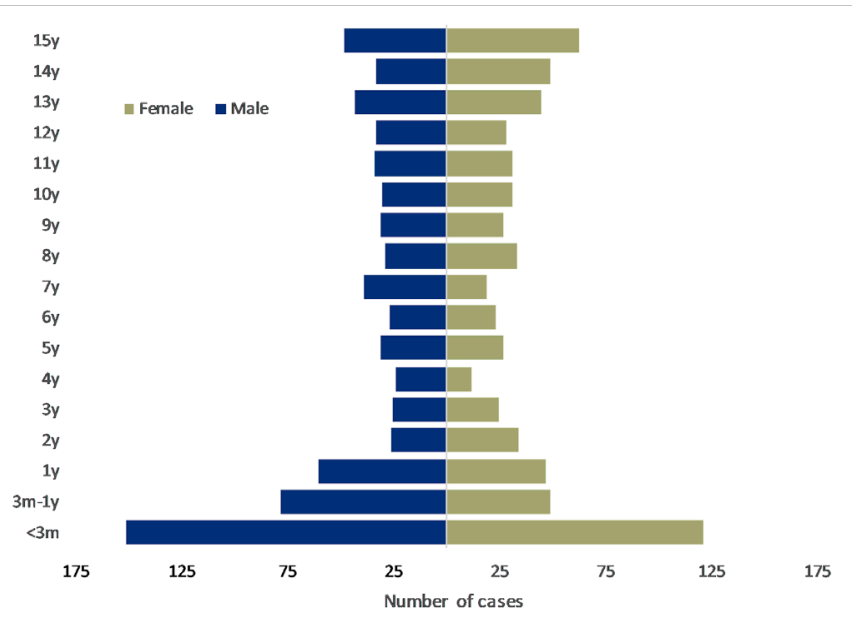

Figure 3 Age distribution of children with confirmed COVID-19 by sex in children during the first pandemic peak (February to May 2020) in England. 


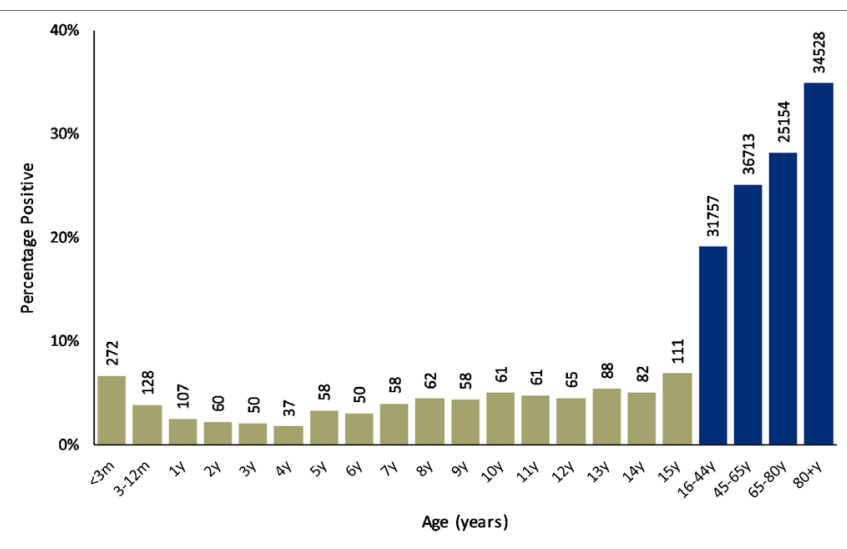

Figure 4 Percentage of test positivity by age group in children (green bar) compared with adults (blue bars) tested for severe acute respiratory syndrome coronavirus 2 during the first pandemic peak (February to May 2020) in England.

(178/959) in those aged 45-64 years, 20.6\% (74/359) in those aged $65-79$ years and $45.5 \%(150 / 330)$ in adults aged $\geq 80$ years (figure 5). Samples were taken throughout the surveillance period and children rarely tested positive at any time, especially those aged 3-9 years, where only 1 of $168(0.6 \%)$ was positive.

\section{Deaths}

There were eight deaths in children with confirmed COVID-19. Four children aged 10-15 years, three of whom had multiple

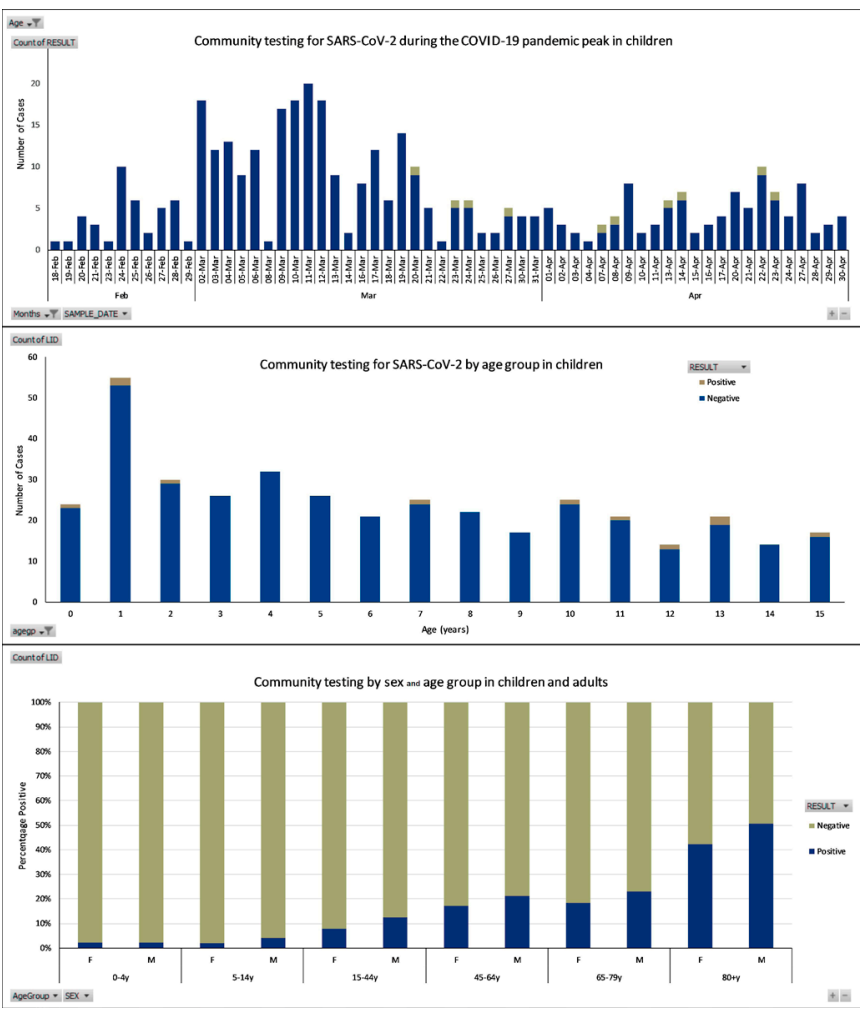

Figure 5 Number of children with acute respiratory infection who were tested for severe acute respiratory syndrome coronavirus 2 (SARS-CoV-2) in general practices across England over the course of the pandemic $(A)$ and by age (B). Figure $3 C$ depicts the proportion of individuals with acute respiratory infection who tested positive by age and sex in England.

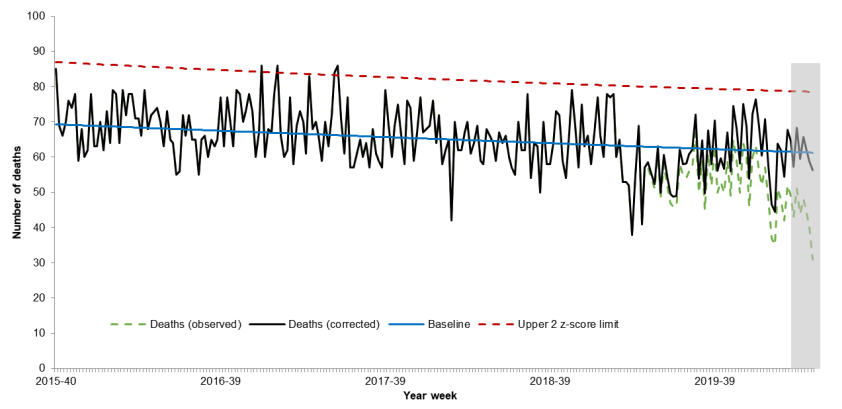

Figure 6 Observed, delay-corrected and expected all-cause deaths in children aged 0-15 years in England from 2015 (week 40) to 2020 (week 18). Data are shown by week of death.

comorbidities, died (CFR, $0.3 \%$; $95 \%$ CI $0.07 \%$ to $0.7 \%$ ) of the infection. In the remaining cases, another cause was identified and SARS-CoV-2 was reported to be incidental or an indirect contributor to death.

\section{Mortality surveillance}

There has been no increase in excess deaths in children aged 0-15 years until 3 May 2020 (figure 6). Between weeks 12 and 18 of 2020, where excess deaths have been reported in other age groups, the cumulative number of corrected daily deaths in children was one fewer than the expected number for this period when compared to the same period in the pre-COVID-19 era.

\section{DISCUSSION}

The experience in England adds to the growing body of evidence on the limited role of children in the COVID-19 pandemic, with just over $1 \%$ of confirmed cases occurring in children. Infants, especially those children aged $<3$ months and those aged 1 year were the most tested age groups and had the highest number of positive cases. With nearly half a million SARS-CoV-2 tests performed during the first 4 months of 2020 , the positivity rate among 35200 children tested was only 4.0\% compared with $19.1 \%-34.9 \%$ in adults and older adults. Community testing of children presenting in primary care with acute respiratory infection identified very low rates of SARS-CoV-2 positivity $(2.8 \%)$ even at the peak of the pandemic, especially among preschool and primary school-aged children. This contrasts with the higher positivity rates with increasing age in adults, reaching nearly $50 \%$ in those aged $\geq 80$ years. Currently, SARS-CoV- 2 positivity rates in the community are low across all age groups. ${ }^{14}$ Reassuringly, the case-fatality rate in children was below $0.5 \%$ with no evidence of excess mortality during the first peak of the COVID-19 pandemic in England.

Other countries with widespread SARS-CoV-2 testing practices have all reported low COVID-19 rates in children, who accounted for only 1\%-3\% of total confirmed cases. ${ }^{3}$ Inclusion of negative test results provides further reassurance of the large numbers of tests performed across all age groups, including children. The lower risk of COVID-19 may be due to lower expression of the cell surface enzyme ACE2 in the nasal epithelium of children compared with adults. ${ }^{15}$ This binds to the SARS-CoV-2 spike protein and promotes internalisation of the virus into human cells. Although clinical follow-up of childhood cases is ongoing, our initial assessment based on the source of paediatric testing suggests that around half the confirmed cases were hospitalised, which compares with 33\% in the USA and $67 \%$ in Italy. ${ }^{16} 17$ Those that were not hospitalised were mainly during the containment phase when close contacts of confirmed cases, 
specifically children of key workers, were screened for the virus, along with children attending the emergency department with acute respiratory infections.

A key unanswered question remains whether asymptomatic children might be contributing to community transmission of SARS-CoV-2. Reports of asymptomatic carriage in children are mainly from active follow-up of contacts of confirmed cases or screening children without adequate follow-up to determine whether they were presymptomatic or truly asymptomatic, ${ }^{18}$ as has been reported in adults. ${ }^{19}$ Although community testing of SARS-CoV-2 in England was not as widespread as some other countries, especially during the peak of the pandemic, our data found that only $4.0 \%$ of children nationally and only $2.8 \%$ of symptomatic children with acute respiratory infection in the community tested positive for SARS-CoV-2.

In Iceland, only 38/564 (6.7\%) children aged $<10$ years who were symptomatic, had recently travelled to high-risk countries or had contact with infected persons, were positive compared with $1183 / 8635(13.7 \%)$ individuals aged $\geq 10$ years. ${ }^{20}$ The difference was more marked in population screening during lockdown when daycare and elementary schools remained open, yet none of 848 children aged $<10$ years were positive compared with 100/12 $232(0.8 \%)$ in children aged $\geq 10$ years. ${ }^{21}$ In the Netherlands, community testing of patients presenting with acute respiratory infection in primary care also did not identify SARS-CoV-2-positive children. ${ }^{22}$ Additionally, children were never the first to be infected or to be the source of infection in the household. ${ }^{22}$ This is supported by other household transmission studies where children of confirmed cases, especially those aged $<10$ years, were significantly less likely to be SARS-CoV-2 positive or becoming symptomatic when compared with adults in the same household. ${ }^{23} 24$ This also applies in educational settings. In New South Wales, Australia, 9 students and 9 staff from 15 schools had confirmed COVID-19 and 735 students and 128 staff were identified as close contacts. ${ }^{25}$ No teacher or staff member, and only one child from a primary school and one child from a high school, may have contracted COVID-19 from the initial school cases. ${ }^{25}$

An unintended consequence of the COVID-19 lockdown on children has been that the national 'Stay at Home' message, along with concerns about acquiring COVID-19 in hospital, discouraged parents from seeking medical help, resulting in large reductions in emergency department attendances and hospitalisation than in previous years. ${ }^{26}{ }^{27}$ This has led to significant concerns about delayed presentations and potentially avoidable fatalities. ${ }^{17}$ Reassuringly however, we were unable to identify any overall excess childhood mortality in England. This contrasts with adult data using the same methodology where high levels of excess mortality were observed in all but the age group of $0-14$ years, and especially among those aged $\geq 85$ years. In England alone, there were an estimated 56456 all-cause excess deaths during the 2 months since 16 March 2020. ${ }^{28}$

Finally, the very low childhood case-fatality rate is reassuring and consistent with the global literature. ${ }^{1}$ In England, regular prospective data linkage using multiple sources allowed rapid capture and follow-up of fatal cases. Recently, however, a small number of children in England presented with hyperinflammatory shock and mixed features of atypical Kawasaki disease and toxic shock syndrome; these children progressed to warm, vasoplegic shock, requiring volume resuscitation and inotropic support. ${ }^{29}$ Since then, similar cases with varying presentations and severities have been reported in other countries that have experienced the COVID-19 pandemic. ${ }^{30}$ Investigations are ongoing to assess the temporal association with SARS-CoV-2.

\section{Strengths and limitations}

The strength of this study is the establishment of a single national surveillance hub with access to multiple local and national data sources in near real-time. The availability of total tests performed was critical to assess any effects of test shortages and changes in testing recommendations. The data also provided insight into the age distribution of confirmed COVID-19 cases; the large numbers of tests performed in infants aged $<3$ months suggested wider testing, potentially including those born to SARS-CoV2-positive pregnant women. The outcomes of SARS-COV-2positive neonates and of infants born to SARS-CoV-2 mothers are being assessed in a national prospective study currently underway in the UK and Ireland. ${ }^{7}$ Similarly, the large number of tests and positive results in older infants and children aged 1 year is likely to reflect wider testing for SARS-CoV-2 in these age group because of frequent presentations with non-specific febrile illnesses. Collecting data across the age groups allowed comparison of children with adults for test positivity overall and in community surveillance of acute respiratory infections in primary care. Limitations include the suboptimal sensitivity of nasopharyngeal and oropharyngeal swabs for SARS-CoV-2. ${ }^{31}$ The lack of reliable serology during the pandemic also meant that cases could not be confirmed retrospectively. Important questions still remain unanswered. We need more information on asymptomatic childhood SARS-CoV-2 infection and transmission as well as seroincidence studies in community and educational settings. Such studies are underway (https://www. gov.uk/guidance/covid-19-paediatric-surveillance) and will become particularly important to ease the lockdown and allow children and teachers safely back to school, and to understand transmission patterns should a second peak emerge.

\section{CONCLUSIONS}

England is currently nearing the end of the first peak of the COVID-19 pandemic. Consistent with other countries, children account for a very small proportion of confirmed cases and have very low case-fatality rates. Despite the large number of children tested, only $4 \%$ were positive for SARS-CoV-2. In the community, SARS-CoV-2 positivity was low even in children presenting with acute respiratory infections. Community transmission and serosurveillance will become increasingly important as lockdown measures are gradually eased.

Contributors SNL is responsible for national surveillance of COVID-19 surveillance in children at Public Health England. All contributed to the results, interpretation and discussion.

Funding The authors have not declared a specific grant for this research from any funding agency in the public, commercial or not-for-profit sectors.

Map disclaimer The depiction of boundaries on this map does not imply the expression of any opinion whatsoever on the part of BMJ (or any member of its group) concerning the legal status of any country, territory, jurisdiction or area or of its authorities. This map is provided without any warranty of any kind, either express or implied.

\section{Competing interests None declared.}

\section{Patient consent for publication Not required.}

Ethics approval Public Health England (PHE) has legal permission, provided by Regulation 3 of The Health Service (Control of Patient Information) Regulations 2002, to process patient confidential information for national surveillance of communicable diseases. This includes PHE's responsibility to monitor the safety and effectiveness of vaccines, and as such, individual patient consent is not required. PHE's Caldicott Guardian approved the collection of data by RCGP RSC to support national surveillance.

Provenance and peer review Not commissioned; internally peer reviewed.

Data availability statement All data relevant to the study are included in the article or uploaded as supplementary information. No additional data available. 
Open access This is an open access article distributed in accordance with the Creative Commons Attribution Non Commercial (CC BY-NC 4.0) license, which permits others to distribute, remix, adapt, build upon this work non-commercially, and license their derivative works on different terms, provided the original work is properly cited, appropriate credit is given, any changes made indicated, and the use is non-commercial. See: http://creativecommons.org/licenses/by-nc/4.0/.

\section{ORCID iD}

Shamez N Ladhani http://orcid.org/0000-0002-0856-2476

\section{REFERENCES}

1 Dong Y, Mo X, Hu Y, et al. Epidemiological characteristics of 2143 pediatric patients with 2019 coronavirus disease in China. Pediatrics 2020.

2 Zimmermann P, Curtis N. Coronavirus infections in children including COVID-19: an overview of the epidemiology, clinical features, diagnosis, treatment and prevention options in children. Pediatr Infect Dis J 2020;39:355-68.

3 Wu Z, McGoogan JM. Characteristics of and important lessons from the coronavirus disease 2019 (COVID-19) outbreak in China: summary of a report of 72314 cases from the Chinese center for disease control and prevention. JAMA 2020. doi:10.1001/jama.2020.2648. [Epub ahead of print: 24 Feb 2020].

4 Zhu J, Zhong Z, Ji P, et al. Clinicopathological characteristics of 8697 patients with COVID-19 in China: a meta-analysis. Fam Med Com Health 2020;8:e000406.

5 Zangrillo A, Beretta L, Silvani P, et al. Fast reshaping of intensive care unit facilities in a large metropolitan hospital in Milan, Italy: facing the COVID-19 pandemic emergency. Crit Care Resusc 2020.

6 Grasselli G, Pesenti A, Cecconi M. Critical care utilization for the COVID-19 outbreak in Lombardy, Italy: early experience and forecast during an emergency response. JAMA 2020. doi:10.1001/jama.2020.4031. [Epub ahead of print: 13 Mar 2020].

7 Ladhani SN, Amin-Chowdhury Z, Amirthalingam G, et al. Prioritising paediatric surveillance during the COVID-19 pandemic. Arch Dis Child 2020;105:613-5.

8 National COVID-19 surveillance reports, 2020. Available: https://www.gov.uk/ government/publications/national-covid-19-surveillance-reports

9 Boddington NLC, Elgohari S, et al. COVID-19 in Great Britain: epidemiological and clinical characteristics of the first few hundred (FF100) cases: a descriptive case series and case control analysis. MedRxiv 2020.

10 Zhao H, Green H, Lackenby A, et al. A new laboratory-based surveillance system (respiratory DataMart system) for influenza and other respiratory viruses in England: results and experience from 2009 to 2012. Euro Surveill 2014;19:20680.

11 Hardelid P, Fleming DM, Andrews N, et al. Effectiveness of trivalent and pandemic influenza vaccines in England and Wales 2008-2010: results from a cohort study in general practice. Vaccine 2012;30:1371-8.

12 de Lusignan S, Correa A, Smith GE, et al. RCGP research and surveillance centre: 50 years' surveillance of influenza, infections, and respiratory conditions. Br J Gen Pract 2017;67:440-1.
13 Vestergaard LS, Nielsen J, Krause TG, et al. Excess all-cause and influenza-attributable mortality in Europe, December 2016 to February 2017. Euro Surveill 2017;22. doi:10.2807/1560-7917.ES.2017.22.14.30506. [Epub ahead of print: 06 Apr 2017].

14 Coronavirus (COVID-19) infection survey pilot: England, 21 may 2020, 2020. Available: https://www.ons.gov.uk/peoplepopulationandcommunity/ healthandsocialcare/conditionsanddiseases/bulletins/coronaviruscovid19infectionsurve ypilot/england21may2020

15 Bunyavanich S, Do A, Vicencio A. Nasal gene expression of angiotensin-converting enzyme 2 in children and adults. JAMA 2020;323:2427.

16 Bialek S, Gierke R, Hughes M, et al. Coronavirus disease 2019 in children - United States, February 12-April 2, 2020. MMWR Morb Mortal Wkly Rep 2020;69:422-6.

17 Parri N, Lenge M, Buonsenso D, et al. Children with Covid-19 in pediatric emergency departments in Italy. N Engl J Med 2020;383:187-90.

18 Munro APS, Faust SN. Children are not COVID-19 super spreaders: time to go back to school. Arch Dis Child 2020;105:618-9.

19 Furukawa NW, Brooks JT, Sobel J. Evidence supporting transmission of severe acute respiratory syndrome coronavirus 2 while presymptomatic or asymptomatic. Emerg Infect Dis 2020;26.

20 Gudbjartsson DF, Helgason A, Jonsson H, et al. Spread of SARS-CoV-2 in the Icelandic population. N Engl J Med 2020;382:2302-15.

21 Gunnarsdottir ELT, Gunnarsdottir SLX, Heimisdottir AA, et al. [Incidence and predictors of prolonged intensive care unit stay after coronary artery bypass in Iceland]. Laeknabladid 2020;106:123-9.

22 Children and COVID-19, 2020. Available: https://www.rivm.nl/en/novel-coronaviruscovid-19/children-and-covid-19

23 Li W, Zhang B, Lu J, et al. Characteristics of household transmission of COVID-19. Clin Infect Dis 2020;382.

24 Cheng H-Y, Jian S-W, Liu D-P, et al. Contact tracing assessment of COVID-19 transmission dynamics in Taiwan and risk at different exposure periods before and after symptom onset. JAMA Intern Med 2020. doi:10.1001/ jamainternmed.2020.2020. [Epub ahead of print: 01 May 2020].

25 COVID-19 in schools - the experience in NSW 2020.

26 A\&E Attendances and Emergency Admissions March 2020 Statistical Commentary, 2020. Available: https://www.england.nhs.uk/statistics/wp-content/uploads/sites/2/ 2020/04/Statistical-commentary-March-2020-jf8hj.pdf

27 Isba R, Edge R, Jenner R, et al. Where have all the children gone? decreases in paediatric emergency department attendances at the start of the COVID-19 pandemic of 2020. Arch Dis Child 2020;105:704.1-704.

28 Sinnathamby MAW, Coughlan H, Bernal L, et al. Excess all-cause mortality observed during the COVID-19 pandemic, England. Submitted for publication 2020.

29 Riphagen S, Gomez X, Gonzalez-Martinez C, et al. Hyperinflammatory shock in children during COVID-19 pandemic. Lancet 2020;395:1607-8.

30 Verdoni L, Mazza A, Gervasoni A, et al. An outbreak of severe Kawasaki-like disease at the Italian epicentre of the SARS-CoV-2 epidemic: an observational cohort study. Lancet 2020;395:1771-8.

31 Bullis SSM, Crothers JW, Wayne S, et al. A cautionary tale of false-negative nasopharyngeal COVID-19 testing. IDCases 2020;20:e00791. 